Удк 636.085.16

\title{
ИССЛЕДОВАНИЕ ФИЗИКО-ХИМИЧЕСКИХ СВОЙСТВ ХРОМОГЕННЫХ КОМПЛЕКСОВ ТРУТОВИКОВ ПЛОСКОГО И ОКАЙМЛЕННОГО
}

\author{
() А.И. Носов ${ }^{1 * *}$, М.А. Сысоева ${ }^{1}$, В.А. Гревцев ${ }^{2}$, Ф.Г. Халитов ${ }^{3}$ \\ ${ }^{1}$ Казанский национальный исследовательский технологический \\ университет, ул. К. Маркса, 68, Казань, Республика Татарстан, 420015 \\ (Россия), e-mail:nosovanig@mail.ru \\ ${ }^{2}$ Центральный научно-исследовательский институт геологии нерудных \\ полезных ископаемых, ул. Зинина, 4, Казань, Республика Татарстан, 420097 \\ (Россия) \\ ${ }^{3}$ Казанский государственный энергетический университет, \\ ул. Красносельская, 51, Казань, Республика Татарстан, 420066 (Россия)
}

Исследована структурная организация хромогенных комплексов трутовиков плоского и окаймленного с помощью методов УФ- и ИК-спектроскопии, электронной микроскопии и фотонно-корреляционной спектроскопии с целью определения их химической природы. Полученные данные позволяют заключить, что исследуемые хромогенные комплексы могут быть отнесены к меланинам.

Ключевые слова: трутовые грибы, хромогенные комплексы, электронная микроскопия, фотонно-корреляционная спектроскопия, меланин, частицы.

Работа выполнена на оборудовании ЦКП «Наноматериалы и нанотехнологии» при финансовой поддержке Министерства образования и науки Российской Федерачии в рамках федеральной целевой программы «Исследования и разработки по приоритетным направлениям развития научнотехнологического комплекса России на 2007-2013 годы» по госконтракту №01201252915 от 28.02.2012. Тема: «Разработка биологически активных добавок на основе супрамолекулярных бионаносистем».

\section{Введение}

В ходе метаболизма трутовые грибы продуцируют широкий спектр соединений, обладающих биологической активностью. К таким соединениям относятся полисахариды (лентинан) [1], терпеноиды (фомитопиниковые кислоты) [2], цереброзиды [3], хромогенные комплексы [4] и др. Поскольку грибные полисахариды являются эффективным средством при лечении онкологических заболеваний, на их основе фирмами Unimed Pharmaceurical Inc, inLife LLC производятся препараты Biolentin Inj, inForce [5, 6]. Наряду с ними фармацевтическая промышленность Российской Федерации выпускает препараты в форме извлечений, которые содержат хромогенный комплекс. Они используются в терапии рака различного происхождения [7].

Носов Антон Игоревич - аспирант, e-mail: nosovanig@ mail.ru Сысоева Мария Александровна - заведующая кафедрой пищевой биотехнологии, доктор химических наук Гревиев Валерий Афанасьевич - старший научный сотрудник, доктор геолого-минералогических наук Халитов Фарит Гусманович - заведующий кафедрой теоретические основы теплотехники, доктор химических наук
На данный момент наиболее изученным грибным хромогенным комплексом является комплекс из чаги (трутовика скошенного, Inonotus obliquus), отнесенный к меланинам. Методами электронной микроскопии и фотоннокорреляционной спектроскопии показано, что меланин чаги в растворе образует полидисперсную систему со средним эффективным радиусом час-

\footnotetext{
* Статья имеет электронный дополнительный материал (приложение): DOI: 10.14258/jcprm.1303195s

Автор, с которым следует вести переписку.
} 
тиц 60-200 нм [8]. Эти частицы состоят из еще меньших частиц, радиусом до 20 нм [9, 10]. С помощью электронной микроскопии показано, что частица меланина чаги сложно организована и состоит из окрашенной темно-коричневой компоненты - хромогена и не окрашенной, представленной белковополисахаридным матриксом [11]. Другой особенностью меланина чаги является наличие большого числа парамагнитных центров - до 9,9·10 18 спин/Г ( $\mathrm{g}=2,0036)$ [12]. Методом ЯМР-релаксации показано, что по молекулярной подвижности меланин имеет двухкомпонентную структуру, причем обе компоненты соответствуют жесткоцепным полимерным формам [13]. Меланин чаги также был исследован с помощью термогравиометрии и дифференциальной сканирующей калориметрии, но указанные методы оказались мало информативны [14]. Для подтверждения структуры меланина широко используют УФ- и ИКспектроскопию [14-19].

Хромогенные комплексы также были выделены и из других видов грибов. Известно, что в плодовом теле трутовика плоского (Ganoderma applanatum) и трутовика окаймленного (Fomitopsis pinicola) coдержатся темно-коричневые хромогенные комплексы, которые, как и меланин чаги, извлекаются из гриба экс-

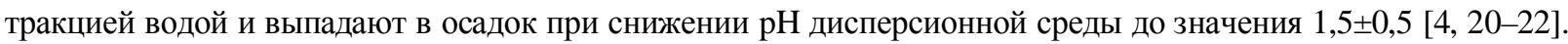
Но их структура пока не установлена.

Для трутовых грибов, включая чагу, источником энергии и углерода служат продукты деградации древесины [23]. Несмотря на различную способность грибов к расщеплению отдельных компонентов древесины можно предположить, что хромогенные комплексы трутовых грибов относятся к меланинам, как и меланин чаги.

Цель работы - определение химической природы хромогенных комплексов трутовиков плоского и окаймленного.

\section{Экспериментальная часть}

Cырье. Плодовое тело трутовика плоского - порядок Poriales, семейство Ganodermataceae, род Ganoderma, вид applanatum Patouillard [24]. Плодовое тело труговика окаймленного - порядок Poriales, семейство Coriolaceae, род Fomitopsis, вид pinicola Karsten [24]. Стерильная часть (наросты) трутовика скошенного (чаги) - порядок Poriales, семейство Hymenochaetaceae, род Inonotus, вид obliquus Pilat [24]. Исследуемые грибы были собраны в Зеленодольском районе Республики Татарстан в октябре в 2010 г.

Экстракцию сырья проводили методом ремацерации согласно [15]. Выделяли хромогенные комплексы по [25]. Качественную реакцию на меланин проводили по методике [26] в растворах хромогенного комплекса с концентрацией $0,1 \%$. Микроскопирование образцов проводили с помощью просвечивающей электронной микроскопии по методике [27] на микроскопе-микроанализаторе ЭММА-4. Размеры частиц определяли согласно [28] в растворе хромогенного комплекса с концентрацией 0,4 мг/мл на фотонном корреляционным спектрометре динамического и статического рассеяния света «PhotoCor Complex». ИКспектры выделенных хромогенных комплексов снимали по методике [29] в таблетках с бромидом калия на ИК-спектрометре Shimadzu с Фурье-преобразованием. УФ-спектры снимали на спектрофотометре UNICO 2800 UV/VIS [29].

\section{Обсуждение результатов}

Для определения химической природы хромогенных комплексов трутовиков плоского и окаймленного необходимо решить вопрос их структурной организации, т.е. возможности их отнесения к меланинам.

Поскольку меланины являются частицами, наиболее информативным методом, позволяющим определить вид и размер частиц хромогенных комплексов трутовиков, является электронная микроскопия. На рисунке приведены снимки хромогенных комплексов трутовиков плоского, окаймленного и меланина чаги. Полученные результаты согласуются с работой [30], где было показано, что частицы хромогенного комплекса могут иметь сложную форму. На снимках «1» и «2» (рис.) показаны скопления частиц хромогенных комплексов трутовиков плоского и окаймленного, которые, как и меланин чаги (рис. -3$)$, состоят из окрашенного (хромоген) и неокрашенного компонентов.

Частицы хромогенных комплексов, так же, как и у меланина чаги, имеют неправильную форму. Их размеры лежат у чаги в пределах 350 нм, у трутовика окаймленного - 200 нм, у трутовика плоского - 100 нм. Это согласуется с данными, полученными с помощью фотонно-корреляционной спектроскопии для исследуемых объектов. Данным методом было показано, что меланин чаги и хромогенные комплексы трутовиков плоского и окаймленного существуют в растворе в виде частиц со средними эффективными диаметрами 322 нм [31], 154 нм и 220 нм соответственно. 
Снимки хромогенных комплексов: 1 - хромогенный комплекс трутовика плоского; 2 - хромогенный комплекс трутовика окаймленного; 3 - меланин чаги [11]

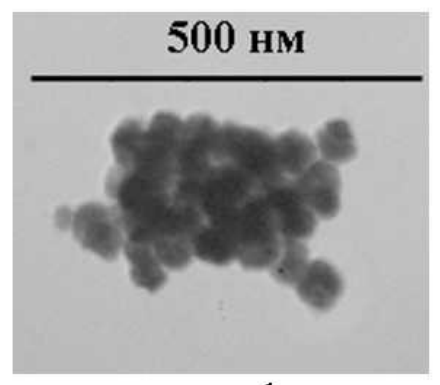

1

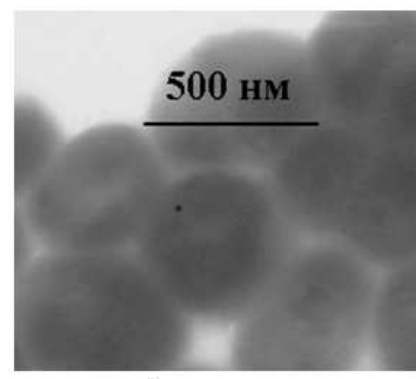

2

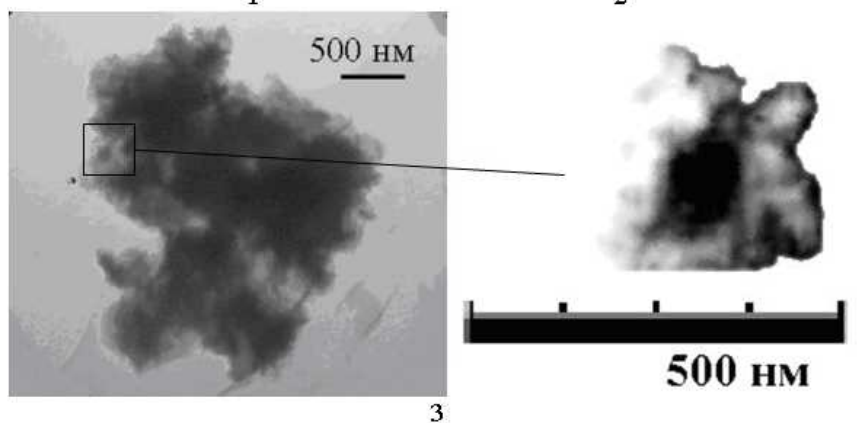

На основании данных, полученных с помощью электронной микроскопии и фотоннокорреляционной спектроскопии, можно заключить, что хромогенные комплексы трутовиков плоского и окаймленного представлены частицами, сопоставимыми по виду и размерам с меланином чаги, и могут быть отнесены к меланинам.

Отнесение хромогенных комплексов трутовиков также проведено с помощью качественных реакций, которые дали положительный результат. Меланины трутовых грибов исследованы с помощью УФ- и ИК-спектроскопии. Методом УФ-спектроскопии показано, что меланин чаги и хромогенные комплексы исследуемых трутовых грибов имеют пик поглощения при длине волны 216 нм. ИК-спектры хромогенных комплексов трутовиков плоского и окаймленного имеют те же характерные для меланинов полосы [14-17], но они не столь интенсивны по сравнению с меланином чаги (см. электронное приложение).

На спектре чаги присутствуют дополнительные интенсивные полосы в области 1240 и $1720 \mathrm{~cm}^{-1}$, соответствующие свободным карбоксильным группам, и полоса амид II в области 1504 см$^{-1}$. Описанные отличия могут быть связаны с различием в организации как хромогена, так и белково-полисахаридного матрикса исследуемых меланинов. Соответствие полос поглощения в спектрах анализируемых объектов указывает на сходство их природы.

\section{Выводы}

Хромогенные комплексы трутовиков плоского и окаймленного отнесены к меланинам. Они сформированы в виде частиц размером 100-350 нм, имеют характерные для меланинов УФ- и ИК-спектры, дают положительную качественную реакцию на меланин.

\section{Электронный дополнительный материал}

В электронном приложении приведены ИК-спектры, обсуждаемые в статье.

\section{Список литературы}

1. Wasser S.P. Medicinal mushrooms as a source of antitumor and immunomodulating polysaccharides // Applied microbiology and biotechnology. 2002. Vol. 60, N3. Pp. 258-274.

2. Yoshikawa K., Inoue M., Matsumoto Y., Sakakibara C., Miyataka H., Matsumoto H., Arihara S. Lanostane triterpenoids and triterpene glycosides from the fruit body of Fomitopsis pinicola and their inhibitory activity against COX-1 and COX-2 // Journal of natural products. 2005. Vol. 68. Pp. 69-73.

3. Striegler S., Haslinger E. Cerebrosides from Fomitopsis pinicola // Monatshefte fur chemie chemical monthly. 1996. Vol. 127. Pp. 755-761.

4. Сысоева М.А., Носов А.И. Получение водных экстрактов трутовых грибов // Бутлеровские сообщения. 2012. T. 30, №4. C. 147-152.

5. Biolentin Inj. (Lentinan) [Электронный pecypc]. URL: http://www.tradekorea.com/productdetail/P00003422/Biolentin_Inj__Lentinan_.html.

6. inForce Regular (PSP+PSK) [Электронный ресурc]. URL: http://www.inforce.co/shop/inforce-regular-psp-pskcoriolus-versicolor. 
7. Якимов П.А. Общая биологическая и химическая характеристика чаги как исходного сырья для получения лечебных препаратов // Чага и ее лечебное применение при раке IV стадии. Л., 1959. С. 36-49.

8. Сысоева М.А., Хабибрахманова В.Р., Гамаюрова В.С., Кудрявцева Л.А. Исследование золя водных извлечений чаги. IX. Определение размеров частиц дисперсной фазы золя извлечений из чаги // Химия растительного сырья. 2008. №2. С. 75-80.

9. Liu Y. Simon J.D. The effect of preparation procedures on the morphology of melanin from ink sac of Sepia officinalis // Pigment cell research. 2003. Vol. 16, N1. Pp. 72-78.

10. Clancy C.M., Nofsinger J.B., Hanks R.K., Simon J.D. A hierarchical self-assembly of eumelanin // Journal of physical chemistry B. 2000. Vol. 104. Pp. 7871-7873.

11. Харина М.В., Хуснутдинов П.Р., Сысоева М.А., Гревцев В.А. Сравнительный анализ меланинов чаги с помощью электронной микроскопии // Пищевые технологии и биотехнологии: сб. тезисов докл. ХІ Международной конференции молодых ученых. Казань, 2010. Ч. 1. С. 285-286.

12. Сысоева М.А., Хабибрахманова В.Р., Минкин В.С., Гамаюрова В.С., Петрашень В.Е. Разделение водных извлечений чаги с использованием этилацетата. II. Парамагнитные свойства хромогенов чаги // Химия растительного сырья. 2007. №4. С. 105-109.

13. Сысоева М.А., Кузнецова О.Ю., Гамаюрова В.С., Суханов П.П., Зиятдинова Г.К., Будников Г.К. Исследование золя водных извлечений чаги. III. Влияние состава сырья на выход экстрактивных веществ водных извлечений чаги // Химия растительного сырья. 2004. №4. С. 29-34.

14. Кукулянская Т.А., Курченко Н.В., Курченко В.П., Бабицкая В.Г. Физико-химические свойства меланинов, образуемых чагой в природных условиях и при культивировании // Прикладная биохимия и микробиология. 2002. T. 38, №1. С. 68-72.

15. Сысоева М.А., Кузнецова О.Ю., Гамаюрова В.С., Халитов Ф.Г. Исследование золя водных извлечений чаги. I. Изменение изучаемой системы при введении комплексонов // Башкирский химический журнал. 2004. Т. 11, №2. С. 62-65.

16. Сысоева М.А., Кузнецова О.Ю., Гамаюрова В.С., Халитов Ф.Г., Суханов П.П. Исследование золя водных извлечений чаги. II. Изменение изучаемой системы при проведении экстракции различными способами // Вестник Казанского технологического университета (КГТУ). 2003. №2. С. 172-176.

17. Сысоева М.А., Хабибрахманова В.Р., Гамаюрова В.С., Шаехова Н.К., Халитов Ф.Г. Исследование золя водных извлечений чаги. ХІІ. Осаждение дисперсной фазы водного извлечения чаги при изменении рН среды // Химия растительного сырья. 2009. №1. С. 131-135.

18. Кузнецова А.Ю., Гамаюрова В.С., Суханов П.П. Структурная организация и свойства полифенолов чаги // Вестник Казанского технологического университета. 2005. №1. С. 244-250.

19. Малама А.А., Бабицкая В.Г., Филимонова Т.В., Щерба В.В., Шинкарчук Б.Н., Марцыганова В.В., Навоша Ю.Ю., Пармон С.В. Характеристика меланинового комплекса, образуемого грибом Alternaria alternate (Fries) Keissler // Прикладная биохимия и микробиология. 1998. Т. 34. №4. С. 426-429.

20. Шиврина А.Н., Ловягина Е.В., Платонова Е.Г. О химическом составе чаги // Чага и ее лечебное применение при раке IV стадии. Л., 1959. С. 55-61.

21. Шиврина А.Н. Гуминоподобные соединения, образуемые древоразрушаемыми грибами // Биологически активные вещества высших грибов. М.-Л., 1965. С. 82-109.

22. Носов А.И., Сысоева М.А., Зиятдинова Г.К., Будников Г.К. Выбор способа экстракции трутовых грибов // Новые достижения в химии и химической технологии растительного сырья : матер. V Bсерос. конфер. Барнаул, 2012. С. 474-475.

23. Шиврина А.Н. К вопросу о биохимии древоразрушающих грибов // Комплексное изучение физиологически активных веществ низших растений. М.; Л., 1961. С. 44-56.

24. Rennert B., Melzig M.F. Screening of selected basidiomycetes for inhibitory activity on Clostridium histolyticum collagenase and human leukocyte elastase // Phytotherapy research. 2002. V. 16, N1. Pp. 81-83.

25. Государственная фармакопея СССР. 11-е изд. М., 1990. 399 с.

26. Лях С.П. Микробный меланогенез и его функции. М., 1981. 273 с.

27. Методические рекомендации № 137. Электронно-микроскопический анализ минералов. М., 2000. 36 с.

28. Zakharova L. Ya., Ibragimova A.R., Kudryavtseva L.A. Nanosized reactors based on polyethylene imines: from microheterogeneous systems to immobilized catalysts // Langmuir. 2007. Vol. 23. Pp. 3214-3224.

29. Казицына Л.А., Куплетская Н.Б. Применение УФ-, ИК- и ЯМР-спектроскопии в органической химии. М., 1971. $264 \mathrm{c}$.

30. Иванова Г.А. Влияние гиперразветвленных полимеров на антиоксидантную активность водных извлечений и меланинов чаги : автореф. дис. ... канд. хим. наук. Казань, 2011. 18 с.

31. Сысоева Е.В. Свойства водных извлечений и меланинов чаги, полученных с применением СВЧ : автореф. дис. ... канд. хим. наук. Казань, 2011. 18 с.

Поступило в редакиию 6 декабря 2012 г.

После переработки 6 августа 2013 г. 
Nosov A.I. ${ }^{{ }^{*}}$, Sisoeva M.A. ${ }^{l}$, Grevtsev V.A. ${ }^{2}$, Khalitov F.G. ${ }^{3}$ THE RESEARCH OF PHYSICAL AND CHEMICAL PROPERTIES OF CHROMOGEN COMPLEXES FROM POLYPORE FRINGED AND POLYPORE FLAT

${ }^{I}$ Kazan national research technological university, C. Marx str., 68, Kazan, Republic of Tatrstan, 420015 (Russia), email:nosovanig@mail.ru

${ }^{2}$ Central scientific-research institute of geology of non-ore minerals, Zinin str., 4, Kazan, Republic of Tatarstan, 420097 (Russia)

${ }^{3}$ Kazan state energetic university, Krasnoselskaya str., 51, Kazan, Republic of Tatarstan, 420066 (Russia)

Structural organization of chromogen complexes from polypore flat and polypore fringed was investigated by means of the UV- and IR-spectroscopy, electron microscopy, photonic-correlative spectroscopy to determine their chemical nature. Obtained data allowed to induce, that studied chromogen complexes can be assigned to melanins. particles.

Keywords: polypore fungi, chromogen complexes, electron microscopy, photonic-correlative spectroscopy, melanin,

\section{References}

1. Wasser S.P. Applied microbiology and biotechnology, 2002, vol. 60, no. 3, pp. 258-274.

2. Yoshikawa K., Inoue M., Matsumoto Y., Sakakibara C., Miyataka H., Matsumoto H., Arihara S. Journal of natural products, 2005, vol. 68, pp. 69-73.

3. Striegler S., Haslinger E. Monatshefte fur chemie chemical monthly, 1996, vol. 127, pp. 755-761.

4. Sysoeva M.A., Nosov A.I. Butlerovskie soobshcheniia, 2012, vol. 30, no. 4, pp. 147-152. (in Russ.).

5. Biolentin Inj. (Lentinan). URL: http://www.tradekorea.com/product-detail/P00003422/Biolentin_Inj__Lentinan_.html.

6. inForce Regular (PSP+PSK). URL: http://www.inforce.co/shop/inforce-regular-psp-psk-coriolus-versicolor.

7. Iakimov P.A. Chaga i ee lechebnoe primenenie pri rake IV stadii. [Chaga and its therapeutic use in cancer stage IV]. Leningrad, 1959. pp. 36-49. (in Russ.).

8. Sysoeva M.A., Khabibrakhmanova V.R., Gamaiurova V.S., Kudriavtseva L.A. Khimiia rastitel'nogo syr'ia, 2008, no. 2, pp. 75-80. (in Russ.).

9. Liu Y. Simon J.D. Pigment cell research, 2003, vol. 16, no. 1, pp. 72-78.

10. Clancy C.M., Nofsinger J.B., Hanks R.K., Simon J.D. Journal of physical chemistry B, 2000, vol. 104, pp. 7871-7873.

11. Kharina M.V., Khusnutdinov P.R., Sysoeva M.A., Grevtsev V.A. Pishchevye tekhnologii i biotekhnologii: sb. te-zisov dokl. XI mezhdunarodnoi konferentsii molodykh uchenykh. [Food Technology and Biotechnology: Book of Abstracts of the XI International Conference of Young Scientists]. Kazan, 2010, part 1, pp. 285-286. (in Russ.).

12. Sysoeva M.A., Khabibrakhmanova V.R., Minkin V.S., Gamaiurova V.S., Petrashen' V.E. Khimiia rastitel'nogo syr'ia, 2007, no. 4, pp. 105-109. (in Russ.).

13. Sysoeva M.A., Kuznetsova O.Iu., Gamaiurova V.S., Sukhanov P.P., Ziiatdinova G.K., Budnikov G.K. Khimiia rastitel'nogo syría. 2004. №4. C. 29-34. (in Russ.).

14. Kukulianskaia T.A., Kurchenko N.V., Kurchenko V.P., Babitskaia V.G. Prikladnaia biokhimiia i mikrobiologiia, 2002, vol. 38, no. 1, pp. 68-72. (in Russ.).

15. Sysoeva M.A., Kuznetsova O.Iu., Gamaiurova V.S., Khalitov F.G. Bashkirskii khimicheskii zhurnal, 2004, vol. 11, no. 2, pp. 62-65. (in Russ.).

16. Sysoeva M.A., Kuznetsova O.Iu., Gamaiurova V.S., Khalitov F.G., Sukhanov P.P. Vestnik Kazanskogo tekhnologicheskogo universiteta (KGTU), 2003, no. 2, pp. 172-176. (in Russ.).

17. Sysoeva M.A., Khabibrakhmanova V.R., Gamaiurova V.S., Shaekhova N.K., Khalitov F.G. Khimiia rastitel'nogo syr'ia, 2009, no. 1, pp. 131-135. (in Russ.).

18. Kuznetsova A.Iu., Gamaiurova V.S., Sukhanov P.P. Vestnik Kazanskogo tekhnologicheskogo universiteta, 2005, no. 1, pp. 244-250. (in Russ.).

19. Malama A.A., Babitskaia V.G., Filimonova T.V., Shcherba V.V., Shinkarchuk B.N., Martsyganova V.V., Navosha Iu.Iu., Parmon S.V. Prikladnaia biokhimiia i mikrobiologiia, 1998, vol. 34, no. 4, pp. 426-429. (in Russ.).

20. Shivrina A.N., Loviagina E.V., Platonova E.G. Chaga i ee lechebnoe primenenie pri rake IV stadii. [Chaga and its therapeutic use in cancer stage IV]. Leningrad, 1959, pp. 55-61. (in Russ.).

21. Shivrina A.N. Biologicheski aktivnye veshchestva vysshikh gribov. [Biologically active substances of higher fungi]. Moscow-Leningrad, 1965, pp. 82-109. (in Russ.).

22. Nosov A.I., Sysoeva M.A., Ziiatdinova G.K., Budnikov G.K. Novye dostizheniia v khimii i khimicheskoi tekhno-logii rastitel'nogo syr'ia: mater. V vseros. konfer. [New advances in chemistry and chemical engineering plant materials: the V All-Russian Conference]. Barnaul, 2012, pp. 474-475. (in Russ.).

23. Shivrina A.N. Kompleksnoe izuchenie fiziologicheski aktivnykh veshchestv nizshikh rastenii. [Comprehensive study of physiologically active substances of lower plants.].Moscow-Leningrad, 1961, pp. 44-56. (in Russ.).

24. Rennert B., Melzig M.F. Phytotherapy research, 2002, vol. 16, no. 1, pp. 81-83.

25. Gosudarstvennaia farmakopeia SSSR. 11-e izd. [State Pharmacopoeia of the USSR. 11th ed.]. Moscow, 1990, 399 p. (in Russ.).

26. Liakh S.P. Mikrobnyi melanogenez i ego funktsii. [Microbial melanogenesis and its functions.]. Moscow, 1981, 273 p. (in Russ.).

\footnotetext{
"Corresponding author.
} 
27. Metodicheskie rekomendatsii №137. Elektronno-mikroskopicheskii analiz mineralov. [Guidelines N137. Electron microscopic analysis of minerals.]. Moscow, 2000, 36 p. (in Russ.).

28. Zakharova L. Ya., Ibragimova A.R., Kudryavtseva L.A. Langmuir, 2007, vol. 23, pp. 3214-3224.

29. Kazitsyna L.A., Kupletskaia N.B. Primenenie UF-, IK- i IaMR-spektroskopii v organicheskoi khimii. [Application of UV, IR and NMR spectroscopy in Organic Chemistry]. Moscow, 1971, 264 p. (in Russ.).

30. Ivanova G.A. Vliianie giperrazvetvlennykh polimerov na antioksidantnuiu aktivnost' vodnykh izvlechenii i melaninov chagi: avtoref. diss. ... kand. khim. nauk. [Influence of hyperbranched polymers on the antioxidant activity of water extracts of melanin and fungus: thesis abstract Ph.D.]. Kazan, 2011, 18 p. (in Russ.).

31. Sysoeva E.V. Svoistva vodnykh izvlechenii i melaninov chagi, poluchennykh s primeneniem SVCh: avtoref. diss. ... kand. khim. nauk. [Properties of aqueous extracts of melanin and fungus obtained using microwave: thesis abstract Ph.D.]. Kazan, 2011, 18 p. (in Russ.).

Received December 6, 2012

Revised August 6, 2013 